\title{
Lazer, Aventura e Risco: reflexões sobre atividades realizadas na natureza
}

Alcyane Marinho*

\begin{abstract}
Resumo: Este artigo tem como objetivo refletir sobre as concepções de aventura e de risco, manifestadas nas atividades realizadas na natureza. Os discursos aqui apresentados estão contidos em uma pesquisa mais ampla, cuja abordagem trabalha com um universo de motivos, aspirações, valores, crenças e atitudes, correspondendo a um espaço mais profundo dos processos, relações e fenômenos. Foi possível perceber que as atividades de aventura na natureza são portadoras de inúmeros significados, relacionando-se a novas descobertas, a novos desafios, à busca pelo desconhecido, ao reencontro consigo mesmo, à incerteza, à espontaneidade, à cooperação, à amizade, entre outros. Tais atividades compreendem diversas formas de experimentação, apontando para além do risco físico, o risco simbólico e imaginário.
\end{abstract}

Palavras-chave: Atividades de lazer. Aventura. Risco. Natureza.

\section{INTRODUÇÃo}

Numa época em que o desenvolvimento tecnológico e as condições de vida (trabalho, moradia, etc.) no meio urbano parecem afastar as pessoas, cada vez mais, do convívio com a natureza, ao mesmo tempo em que o desenvolvimento econômico segue destruindo o meio ambiente em escala planetária, é sintomático que um número crescente de pessoas procure passar momentos agradáveis e emocionantes junto à natureza. Embora a idéia de aventurar-se em expedições não seja nova, há motivações, significados e conseqüências claramente peculiares à época em que vivemos, especialmente quando pensamos em atividades de aventura na natureza.

"Docente da Universidade do Sul de Santa Catarina (UNISUL) e da Universidade do Estado de Santa Catarina (UDESC), Florianópolis (SC). Pesquisadora do Laboratório de Estudos do Lazer (LEL) da UNESP de Rio Claro (SP). Brasil. E-mail: alcyane.marinho@ hotmail.com 
Tais atividades estão sendo entendidas como as diversas práticas manifestadas, privilegiadamente nos momentos de lazer, com características inovadoras e diferenciadas dos esportes tradicionais, pois as condições de prática, os objetivos, a própria motivação e os meios utilizados para o seu desenvolvimento são outros e, além disso, há também a presença de inovadores equipamentos tecnológicos, permitindo uma fluidez entre o praticante e o espaço da prática terra, água ou ar. São atividades cerceadas por riscos e perigos, na medida do possível, calculados, não ocorrendo treinamentos intensivos prévios (como no caso dos esportes tradicionais e de práticas corporais como a ginástica e a musculação). A experimentação acontece de maneira mais direta, havendo um afastamento de rendimentos planejados. Outras características e discussões específicas contextualizadoras destas práticas podem ser vislumbradas em outros escritos (MARINHO, 2001; MARINHO; BRUHNS, 2005, 2003, 2001).

O lazer, neste sentido, parece ser um interessante ponto de partida para aguçar a compreensão das mais variadas relações que se estabelecem, a cada dia, entre os seres humanos, desde que não seja considerado de forma isolada, mas em profunda relação com outras esferas da vida humana: política, econômica, religiosa, etc.

O surgimento de novas tecnologias, criadoras de novas possibilidades de vivências no lazer, conduz a um repensar sobre os significados de proximidade, distância, individualidade, sociabilidade, mobilidade, meio ambiente e aventura.

Acreditando que "[...] as sensibilidades de uma época se inserem na cultura dessa época" (GEERTZ, 2001, p. 31), a intenção deste artigo é refletir sobre as atividades de aventura na natureza como possibilidades férteis para o entendimento das relações que se estabelecem, na nossa contemporaneidade, entre os seres humanos e a natureza, a partir de envolvimentos mais descompromissados e efêmeros, porém, verdadeiros e intensos.

Inúmeros fatores indicam o crescimento expressivo da visitação em áreas naturais no Brasil e no mundo e, de acordo com uma pesquisa realizada pelo Ministério do Meio Ambiente, as atividades

Movimento, Porto Alegre, v. 14, n. 02, p. 181-206, maio/agosto de 2008. 
de aventura na natureza enquadram-se entre os segmentos mais promissores do mercado de turismo, com um crescimento mundial estimado entre $10 \%$ e $30 \%$ ao ano (BRASIL, 2006).

Outras iniciativas também são emblemáticas e contribuem para situar o fenômeno. São elas: crescente produção científica; maior visibilidade e reconhecimento em eventos científicos em várias áreas do conhecimento, nos âmbitos regional, nacional e internacional; oferecimento de disciplinas optativas e obrigatórias, cursos de extensão, graduação e pós-graduação principalmente (mas não só) nas áreas de Educação Física e Turismo, em diversas faculdades e universidades do Brasil; desenvolvimento de inúmeros trabalhos com diferentes populações: idosos (DIAS, 2006); crianças (INÁCIO et al., 2005); portadores de necessidades especiais (CARVALHO, 2005; MUNSTER, 2004); dependentes de drogas (GIMENO et al., 2000); entre outras iniciativas.

Complementar, aliviar, recompensar, ir além ou re-encantar o estar no mundo foram metas das sociedades ocidentais modernas e, nos dias atuais, elas ainda prevalecem, em diferentes níveis e a partir de novas configurações. Os vários tipos de fanatismos religiosos; as ressurgências étnicas; a manifestação de novas "tribos" (MAFFESOLI, 1995); as efervescências musicais e esportivas; o consumismo exacerbado (FEATHERSTONE, 1997); as instabilidades diversas no trabalho e no emprego (SENNET, 2000); a exaltação/exploração da natureza e das paisagens (LUCHIARI, 2000) são alguns exemplos do contexto no qual está inserido o referido desejo de re-encantamento do mundo.

A aventura na natureza oportuniza o estabelecimento de novas relações entre os envolvidos no lazer e em outras esferas da vida humana, criando novos laços de amizade e proporcionando novas sensações e emoções. Assim, mostra-se uma oportunidade fecunda para que pensemos a vida social contemporânea, com base no contexto ilustrado.

Nesta perspectiva, este artigo tem como objetivo específico refletir sobre as concepções de aventura e de risco, manifestadas nas atividades realizadas na natureza, trazendo discussões contidas

Movimento, Porto Alegre, v. 14, n. 02, p. 181-206, maio/agosto de 2008. 
em uma pesquisa mais ampla ${ }^{1}$, cuja trilha metodológica está apresentada a seguir.

\section{Apresentando a Pesquisa}

A pesquisa, por meio da qual os dados apresentados neste artigo foram coletados, refere-se a uma investigação na área de estudos do lazer.

Como pesquisa qualitativa, a abordagem trabalha com um universo de motivos, aspirações, valores, crenças e atitudes, correspondendo a um espaço mais profundo dos processos, relações e fenômenos, os quais não podem ser reduzidos à operacionalização de variáveis, como esclarece Minayo (1993).

As fundamentações conceituais sobre a temática abordada foram buscadas, principalmente, junto à Sociologia, Educação Física e Antropologia, áreas estas as quais, conjuntamente, contribuem e sustentam as discussões estabelecidas. No sentido de superar as diversas compartimentações acadêmicas, estas áreas estão sendo visualizadas como parte integrante de um todo, inter-relacionando-se no contexto de suas especificidades e complexidades.

O estudo foi desenvolvido, concomitantemente, por meio de duas pesquisas complementares. Uma constituiu-se de uma pesquisa bibliográfica, da qual fizeram parte os levantamentos bibliográficos relacionados às temáticas das atividades de aventura na natureza, tais como a caminhada, a escalada, dentre outras. A pesquisa bibliográfica visou a uma fundamentação filosófica e teórica do problema, possibilitando um aprofundamento conceitual e terminológico.

A outra referiu-se a uma pesquisa de campo, baseada em dois instrumentos (entrevista semi-estruturada e observação participante), permitindo a investigação dos motivos que fazem as pessoas

\footnotetext{
${ }^{1}$ MARINHO, Alcyane. As diferentes interfaces da aventura na natureza: reflexões sobre a sociabilidade na vida contemporânea. 2006. Tese (Doutorado em Educação Física) - Faculdade de Educação Física. Universidade Estadual de Campinas, Campinas (SP), 2006. Orientação: Dra. Heloisa Turini Bruhns.
}

Movimento, Porto Alegre, v. 14, n. 02, p. 181-206, maio/agosto de 2008. 
deslocarem-se para ir ao encontro das atividades de aventura na natureza, bem como o gosto dessas pessoas, comportamentos, valores, etc.; as formas de envolvimento dos praticantes com essas atividades e como se dá a interação entre os grupos de praticantes; como se estabelecem as relações das atividades de aventura na natureza com o cotidiano urbano, no trabalho, na família, etc.; ou seja, como tais vivências relacionam-se com o dia-a-dia dos praticantes. Todas estas investigações estavam atreladas ao interesse principal: como os praticantes percebem a aventura e a natureza.

Os sujeitos/atores deste estudo possuíam experiência prévia em atividades em contato com a natureza, tornando-os, em parte, diferenciados dos novos adeptos que emergem a cada dia, os quais, muitas vezes, são impulsionados apenas pelo desejo de distinção ao fazer algo novo, pelo modismo ou simples consumo.

Não houve pretensão em limitar um perfil dos entrevistados, por isso ele se mostra tão diversificado. Contudo, para fins de melhor retorno e aprofundamento nas respostas, a opção foi por pessoas que já haviam tido contato prévio com a natureza em atividades diversas.

As viagens e a escolha pelas pessoas investigadas foram realizadas de maneira aleatória, de acordo com o interesse de ambos: pesquisado e pesquisador.

A interação com cada pessoa investigada ocorreu em múltiplos momentos e de diferentes formas, mostrando uma variedade nas maneiras pessoais de relacionamento com a atividade.

Neste artigo, os sujeitos/atores recebem a denominação de entrevistado 1, 2, 3 e assim por diante, com o intuito de preservar suas identidades.

Como técnica, a observação participante (BRANDÃO, 1988) permitiu situações de relativa proximidade com os indivíduos pesquisados.

As observações focaram, privilegiadamente, os comportamentos dos investigados que dessem indícios dos motivos que os conduzem a buscar o contato com a natureza; as atitudes que demonstrassem

Movimento, Porto Alegre, v. 14, n. 02, p. 181-206, maio/agosto de 2008. 
seus valores e princípios atrelados ao meio ambiente e, também, os comportamentos que evidenciassem formas de envolvimento nas atividades e com as pessoas participantes naquelas situações na natureza.

Por sua vez, com as entrevistas semi-estruturadas (SEVERINO, 1992), foi possível que os entrevistados, seguindo a linha de seus próprios pensamentos e de suas experiências, participassem conjuntamente do processo de elaboração da pesquisa.

As observações e entrevistas ocorreram, principalmente, em algumas viagens que realizei com grupos para locais naturais, tais como: Parque Estadual Turístico do Alto Ribeira (PETAR); Parque Nacional de Itatiaia (MG; SP); Visconde de Mauá (RJ); Brotas (SP); Analândia (SP), Chapada dos Veadeiros (GO) e Serra da Canastra (MG). Estes locais são bastante reconhecidos por sua beleza e por seus atrativos naturais, sendo muito visitados ao longo de todo o ano. As viagens a estes locais ocorreram, principalmente, durante finais de semana e feriados prolongados.

As informações obtidas com a observação participante foram confrontadas com os dados coletados por meio da entrevista semiestruturada.

De acordo com a disponibilidade dos envolvidos, foram agendados horários para a realização das entrevistas e a maior parte delas foi gravada, sendo que algumas foram filmadas para, posteriormente, serem transcritas e analisadas. Delas, foram resgatados os dados principais e mais relevantes aos objetivos deste estudo, por meio de análise de conteúdo. As observações também foram registradas por meio da utilização do diário de campo. Instrumento este de suma importância, pois sem ele teria sido impossível o registro daquilo que não se grava.

A partir desta trilha metodológica, a pesquisa pretendeu compreender como os praticantes percebem a aventura e a natureza. Para além disso, conforme códigos e convenções, os quais representam as relações sociais próximas ao grupo e sua racionalidade, $\mathrm{o}$ estudo tentou captar os significados implícitos que constituem o fenômeno atual da aventura.

Movimento, Porto Alegre, v. 14, n. 02, p. 181-206, maio/agosto de 2008. 
Nesta perspectiva, este artigo privilegia as discussões referentes especialmente à aventura e suas interfaces com o risco, o desconhecido e a exploração.

\section{Aventura, RISCO, DESCONHECIDO E EXPLORAÇÃo}

"Mas, filho, para que serve uma viagem dessas?", perguntaram os tios de Amyr Klink, primeira pessoa a velejar sozinho, a bordo de seu veleiro Paratii, ao longo de cinco meses, com o intuito de circunavegar a Antártica (feito este nunca antes conseguido). Klink (2000, p. 205) responde:

[...] precisamente para nada, e não há de fato nada de útil em viajar meses a fio para simplesmente voltar ao ponto de partida. Porém, a inútil circunavegação que eu completara era a minha realização mais deliciosa. Difícil explicar. Há montanhas de inutilidades na história da humanidade, atos e obras que se tornaram importantes pelo simples fato de estarem completos, pelo modo como foram feitos, pelo símbolo que representam. Completar a viagem era a mais importante tarefa que eu tinha pela frente.

Experiências deste tipo têm despertado o interesse de diferentes estudiosos, no sentido de desvendar a busca pela aventura. De acordo com alguns autores (EWERT, 1989; DONNELLY; WILLIANS, 1985), as atividades de aventura ocorridas em momentos de lazer e, ainda, de turismo (haja vista que muitas delas ocorrem ao longo de viagens), de alguma forma, parecem estar relacionadas com o elemento risco ${ }^{2}$.

É pertinente evocar Le Breton (2006, p. 107-108), autor que tem investigado especificamente as atividades de risco na natureza,

\footnotetext{
${ }^{2}$ Lembrando que deve ser considerada a principal diferenciação entre as palavras perigo e risco. Enquanto a primeira é imprevisível; a segunda é previsível e sua probabilidade pode ser calculada, de acordo com níveis de exposição dos envolvidos, entre outros aspectos. Contudo, vale destacar que a expressão risco tem sido utilizada indiscriminadamente tanto para práticas de risco real quanto imaginário.
}

Mavimento, Porto Alegre, v. 14, n. 02, p. 181-206, maio/agosto de 2008. 
focando práticas que, de fato, podem causar mortes. O autor desenvolve a idéia de "ordálio" ("provação extrema") incorporado nas atividades de risco como uma forma de "jogo liberado com a morte". São emblemáticos, neste caso, o base jump (salto de uma altura mínima necessária para a abertura do pára-quedas), a escalada solo (praticada sozinho e sem utilização de nenhum equipamento), o esqui extremo (realizado fora das pistas convencionais e asseguradas), dentre várias outras modalidades.

O que, segundo Ewert (1989), marcadamente define uma atividade de aventura é a busca deliberada pelo risco e a incerteza do resultado. $\mathrm{O}$ risco adquire um papel significativamente importante no que tange à satisfação com a experiência, sendo que o desejo de participar pode diminuir se tais riscos não existirem. Igualmente, $\mathrm{o}$ excesso de risco em uma aventura pode resultar na diminuição da satisfação e, até mesmo, na perda do desejo de participação.

Neste sentido, o elemento risco constitui-se em uma construção multimensional, na qual o reconhecimento e a pesquisa das dimensões psicológicas, físicas e sociais podem ter implicações relevantes na administração da experiência de aventura.

Vale lembrar que, apesar de muitas vezes as pessoas considerarem a palavra risco negativamente, ela também é associada à busca de resultados positivos. Para Swarbrooke (2003), as percepções do risco estão diretamente vinculadas à capacidade, à experiência e ao conhecimento da pessoa com relação à atividade de aventura.

Este autor, apoiado em algumas pesquisas sobre a temática, acredita que pessoas com altos níveis de experiência em montanhismo, por exemplo, tendem a perceber o risco como um desafio e não como um perigo. Ao invés de sentirem-se ameaçadas pelo nível de risco nas montanhas, essas pessoas sentem que o risco contribui, de forma positiva, na aquisição de satisfação. Uma pessoa, então, que nunca praticou montanhismo, pode experimentar um nível de risco desconfortável e incontrolável; contudo, assim que esta mesma pessoa se familiarizar mais com tal prática, passará a perceber o componente risco mais positivamente.

Movimento, Porto Alegre, v. 14, n. 02, p. 181-206, maio/agosto de 2008. 
O risco representa algo indissociável da aventura. Ele expressa uma probabilidade de que algo inesperado aconteça, apenas momentaneamente, podendo, igualmente, acarretar situações positivas e prazerosas. Isso foi detectado na fala do entrevistado 1 , professor e condutor de trilhas:

Quando eu fiz uma prova de ironman, por exemplo, e outras provas difíceis de mountain bike, no momento ali do sofrimento, do risco, eu pensava: "nossa, nunca mais vou fazer isso", "chega", "tá bom", mas quando passou uma semana, eu comecei a ter lembranças e já estava querendo alguma coisa pior que aquilo. No sofrimento, no risco, você jura que não vai fazer de novo, mas a hora que você chega, respira, vê que não está faltando nenhum pedaço, que sobreviveu, vem aquela vontade enorme de fazer de novo!

Pesquisando em estudos de autores, como os aqui abordados, em teorias de sociólogos, como Simmel (1988) e, até mesmo, em dicionários de Língua Portuguesa ${ }^{3}$, pode-se verificar que os conceitos de aventura estão, na maioria das vezes, relacionados, de alguma forma, com estas idéias de risco, imprevisto e incerteza.

Contudo, tanto quanto a busca por situações de risco, a base das atividades de aventura desenvolvidas na natureza também parece aproximar-se da procura por situações novas, desafiadoras e transmissoras de novos conhecimentos.

Por isso, a iniciativa aqui empreendida é questionar se as definições e conceituações existentes são suficientes para uma compreensão mais aprofundada do termo aventura. Há a necessidade de serem inseridos outros elementos para a discussão, tais como: experiência subjetiva dos indivíduos e percepção do que é aventura. A consideração desses elementos pode conduzir a um entendimento mais amplo e, também, mais profundo da questão.

\footnotetext{
${ }^{3}$ Entre alguns significados da palavra aventura, no Novo Dicionário da Língua Portuguesa (FERREIRA, 1975), é possível destacar os seguintes: "[...] experiência arriscada, perigosa, incomum, cujo fim ou decorrências são incertas [...]; acontecimento imprevisto, surpreendente, peripécia [...]".
}

Movimento, Porto Alegre, v. 14, n. 02, p. 181-206, maio/agosto de 2008. 
De antemão, é preciso enfatizar que o conceito de aventura é dinâmico e possui diferenças significativas quando são comparados determinados fatos e épocas.

$\mathrm{Na}$ atualidade, Schwartz (2002) ressalta que a aventura passa a ser utilizada para a divulgação de mensagens positivas de vida, propondo a geração de auto-estima favorável, de certo status e, até mesmo, de uma possível noção de preservação.

A transmissão dessas mensagens positivas pode ser visualizada nos mais variados meios de comunicação, a partir do uso da expressão aventura para o comércio de bens e serviços, tais como viagens, carros, seguros de vida, roupas, comidas, etc. Neste sentido, a aventura passa, até mesmo, a estabelecer um padrão de felicidade. Há que se refletir, além disso, sobre o apelo ecológico vazio de várias dessas iniciativas, as quais, muitas vezes, nada têm de ecológico.

Weber (2001) afirma que a experiência subjetiva da aventura dos indivíduos e suas próprias percepções podem não ser condizentes com certas classificações e definições de pesquisadores e estudiosos da área. Este fato, por sua vez, tem várias implicações na vivência, na pesquisa, na administração e no marketing das atividades de aventura na natureza. É preciso destacar, ainda, que fatores como características da personalidade e experiências anteriores com as atividades interferem diretamente na percepção da aventura dos praticantes.

Portanto, nesta discussão, não se pode deixar de levar em consideração a subjetividade associada a maior ou menor predisposição para a exposição em atividades arriscadas. $\mathrm{O}$ entrevistado 2 , fotógrafo e condutor de trilhas, mostra sua percepção e seu interesse pela aventura, bastante diferenciados daqueles apontados pelo entrevistado 1, anteriormente apresentados:

Eu não sei se eu sou um grande praticante nem estimulador da aventura; mas talvez eu seja mais um bom estimulador e praticante da contemplação. Eu acabo chamando mais a atenção pras plantas, pra vegetação, pra possibilidade de encontrar bichos no caminho. Pra mim a aventura é muito mais

Movimento, Porto Alegre, v. 14, n. 02, p. 181-206, maio/agosto de 2008. 
estética que uma aventura física. É mais uma busca da imagem, do visual e isso tem muito a ver com a minha formação (atualmente sou fotógrafo) e acho que isso é uma outra forma de fazer turismo e de se aventurar no mato. É um outro olhar, eu diria.

Outros aspectos interligados a este (subjetividade), também devem ser considerados e dizem respeito à tomada de decisão e ao ambiente. Sobre este último aspecto, Walle (1997) argumenta que o comportamento aventureiro é, geralmente, reconhecido não simplesmente por envolver lugares excitantes, pois nem todas as atividades ocorridas ao ar livre ou junto à natureza se constituem em uma aventura. A entrevistada 3, arquiteta, em seus depoimentos, dá indícios de concordar com isso, afirmando que:

[...] nem sempre as atividades na natureza são uma aventura. Eu acho que o que caracteriza uma aventura é a novidade, o desafio de você ir para um lugar novo que você não sabe o que vai acontecer, como vai ser o percurso, você não sabe o que, nem quem poderá encontrar no caminho; tem um começo, mas você não sabe como será o fim. Às vezes vencer dificuldades físicas mesmo. Mas, por outro lado, isso nem sempre acontece quando você vai várias vezes para o mesmo lugar, pelo mesmo caminho, fazendo o mesmo percurso; aquilo se torna mais habitual. Então, eu não sei se eu poderia chamar isso de aventura, pois eu já sei o que vai acontecer. Podem ter algumas surpresas, mas eu não sei se elas podem ser chamadas de aventuras [...]. Eu acho que aventura é mais o desafio de alguma coisa nova, de enfrentar o novo ou de descobrir alguma coisa que eu nem imaginaria que pudesse estar ali, de fazer uma descoberta mesmo.

Conforme Ewert e Hollenhorst (1989), mesmo que, em determinadas situações, os participantes procurem aumentar os níveis de dificuldade e as oportunidades de desafios, eles não buscam, necessariamente, níveis mais elevados de risco.

É possível que haja, simplesmente, a manifestação de elementos que visem a ultrapassar limites, os quais não necessariamente estejam

Movimento, Porto Alegre, v. 14, n. 02, p. 181-206, maio/agosto de 2008. 
ligados a riscos, mas a novas descobertas e novos desafios. O entrevistado 4, espeleólogo e professor, aponta alguns indicativos desta situação:

[...] eu entendo como aventura você buscar ultrapassar os seus limites. A partir do momento em que você tem conhecimento de um espaço, de uma atividade e você quer ultrapassar estes limites, você está se colocando em um momento de aventura e dentro da caverna isso acontece em todos os momentos. Mesmo que você vá fazer uma pesquisa científica, você está praticando uma aventura, você está indo além do seu conhecimento. Acho que todo mundo que vai pra caverna, acaba pensando em um momento de aventura. É diferente, por exemplo, quem faz um deslocamento para um lugar já conhecido, uma praia. Ele está tendo um lazer, mas que algo mais ele está buscando além daquilo que ele já conhece? Da praia?

Mais que ultrapassar limites, o discurso acima parece salientar que a idéia da aventura está muito mais relacionada à busca do desconhecido que possa agregar conhecimentos. A experimentação em uma caverna, para este entrevistado, é um palco perfeito para isso:

[...] dentro da caverna, em todos os momentos, você está vivendo uma aventura. Você estará sempre vendo novidades. Por exemplo, se você entrar em uma caverna turística, como a Caverna do Diabo, ela está iluminada, ela tem corrimão, ela tem escadas, mas mesmo assim parece que você está entrando num espírito de aventura. E se você chegar lá no final dela e apagar a luz? O que você vai fazer, sentir? Então você tem sempre essa imagem de algo escuro, de algo que pode acontecer. É diferente de você ir pra praia porque você não imagina algo que possa acontecer além daquilo que já é tradicional. Quando você está dentro de uma caverna, no subsolo, você está sempre esperando algo de diferente acontecer e lá você sempre descobre algo novo [...] mas, para se chegar até este "novo", os obstáculos devem ser transponíveis!

Movimento, Porto Alegre, v. 14, n. 02, p. 181-206, maio/agosto de 2008. 
Além da exaltação do aspecto desconhecido, para este praticante, a aventura também necessita ser superada, ou seja, precisa ser possível de ser vivida, apesar das dificuldades inerentes à prática, no caso, a visitação às cavernas; caso contrário, a atividade pode vir a ser desmotivante.

Ao ser questionada sobre seus interesses e expectativas nas atividades de aventura na natureza, a entrevistada 3 corrobora e complementa as afirmações deste praticante:

[...] o dia-a-dia na cidade é muito maçante, é muito corrido. Eu saio da minha casa de manhã, vou para o escritório, fico umas $9 \mathrm{~h}$ por lá e volto pra casa. Eu já tenho atividades pra fazer em casa, além de estudar. Então, eu acho que procurar por atividades fora do meio urbano, numa área rural, funciona como um refúgio. É buscar coisas diferentes, buscar novidades, conhecer pessoas novas, apreciar a paisagem. Tanto na serra quanto no litoral, o Brasil tem lugares maravilhosos!

Implementando a discussão, a concepção de aventura da professora entrevistada 5, também demonstra questões importantes.

\begin{abstract}
Aventura pra mim não é adrenalina. Detesto!!!! Não gosto mesmo! Aventura pra mim é você fazer uma coisa sem planejar muito. Eu sei onde eu quero chegar, eu sei o que eu quero fazer, só que eu não sei como a coisa vai rolar. Ela vai acontecer naturalmente. Pra mim, no nosso dia-a-dia, dentro da ciência, da consultoria, dentro dos projetos tem que ser tudo milimetricamente planejado e eu detesto isso [...]. Então, como você compensa isso? Como você tem atitudes compensatórias dentro desse cotidiano rígido que tem que ser tão bem planejado? Não planejando! Eu fiquei doente porque eu não estava tendo mais a oportunidade de fazer viagens em que eu pudesse desligar disso tudo. Quando eu viajo, eu procuro me perder, porque eu acho que é se perdendo que você conhece os lugares, as pessoas, que você se encontra. A gente se perde e depois a gente se acha. E quando a gente se acha, a gente se acha não só geograficamente, mas psicologicamente também e nos dá uma sensação de que nós podemos nos encontrar das duas formas.
\end{abstract}

Movimento, Porto Alegre, v. 14, n. 02, p. 181-206, maio/agosto de 2008. 
Os discursos apresentados, de fato, enfatizam que os adeptos das atividades de aventura na natureza insistem sobre a falta de estímulo e liberdade em suas vidas, demarcando existências superprotegidas pelas regras sociais e pelo conforto técnico das sociedades. "A rotina, ou melhor, a segurança que envolve a existência, suscita, por vezes, o tédio. Ela alimenta a busca regular de uma intensidade que habitualmente não existe" (LE BRETON, 2006, p. 101).

Por isso, talvez possamos, efetivamente, afirmar que a aventura compreende a liberdade de escolha pelo tipo e nível da atividade em si (mais ou menos arriscada, estressante, cansativa); o componente incerteza, diretamente ligado ao desconhecido, ao novo e, também, recompensas inerentes à prática (satisfação, bem-estar, superação, alegria, etc.).

A espontaneidade, nesta perspectiva, é uma outra característica que também aparece no interdito do discurso de alguns praticantes e é muito pertinente para a discussão das atividades de aventura na natureza. Os diversos tipos de repressões (políticas, religiosas, etc.) pelos quais passaram os seres humanos ao longo da história, de certa forma, tolheram o lado aventureiro da vida. Neste sentido, as atividades de aventura na natureza parecem despertar aspectos menos controlados, tais como atitudes hedonistas, cooperativas, sensibilizadoras, deslocamentos, experimentações, dentre outras possibilidades.

No entanto, é preciso lembrar que o contrário também pode ser verdadeiro quando nos remetemos, por exemplo, àqueles pacotes fechados de ecoturismo em que tudo é detalhadamente estruturado (horário do café, horário dos passeios, do almoço, do jantar, do ficar à toa, etc.) impedindo comportamentos e atitudes mais livres e flexíveis, limitando, de fato, o aproveitamento da viagem, pois tudo deve ser feito de acordo com padrões pré-determinados e não se pode atrasar, atrapalhando o grupo. Portanto, as atividades de aventura na natureza, podem tanto despertar a espontaneidade nas pessoas, quanto tolher e inibir tal comportamento, devido à forma de condução de um grupo por um guia, por exemplo.

Movimento, Porto Alegre, v. 14, n. 02, p. 181-206, maio/agosto de 2008. 
A entrevistada 5 traz outros elementos para refletirmos:

Eu não gosto de nada que tem altura; eu não gosto de subir, prefiro descer. Então eu mergulho, gosto de lugares bem verdes, tipo mato mesmo. Estar na natureza, pra mim, é um momento de contemplação, de re-encontro comigo mesma; onde eu me re-equilibro, ouvindo os sons da natureza. É como se eu limpasse a minha mente. É muito tranqüilo, é muito gostosa esta sensação. Pra mim serve, inclusive, pra avaliar a minha vida; o que você quer, o que você sonha.

A fala da entrevistada 3 também é ilustrativa neste contexto, enfatizando, assim como nos dizeres da professora acima, que o estar na natureza pode ser compensatório; o que não torna a experiência menos importante:

Esses refúgios na natureza são essenciais pra minha vida! É onde eu descanso, onde eu consigo restabelecer as minhas energias e ter pique pra continuar as minhas atividades na cidade; que é onde eu vivo. [...] quando eu volto, é muito gratificante! Eu trabalho muito com a criatividade e acho que essa renovação, esse contato com a natureza é importante! Eu acho que aumenta muito mais a minha criatividade, me deixa muito mais solta, mais desprendida do cotidiano que vai se tornando maçante com o tempo.

Contudo, quando envolve riscos e o medo se sobressai, a aventura revela outros componentes. A entrevistada 5 não hesita em comentar a experiência de seu primeiro mergulho que não foi muito satisfatório, pelo menos inicialmente.

Eu não gosto de sentir medo, isso me faz mal! No meio de uma situação de pânico, durante meu primeiro mergulho, a mais de $15 \mathrm{~m}$ de profundidade, a minha máscara não parava de alagar e eu não me lembro de ter tido tanto desespero na minha vida.

Comentando o desfecho da situação acima, a praticante também chama a atenção para a relação de confiança e amizade manifestada nas atividades de aventura na natureza:

Movimento, Porto Alegre, v. 14, n. 02, p. 181-206, maio/agosto de 2008. 
[...] um amigo percebeu o meu desespero, aproximouse e me transmitiu confiança, pegou na minha mão e fez um carinho. Acho que era tudo o que eu precisava pra superar aquele pânico e me sentir bem naquele ambiente diferente.

A natureza deixa de ser um objeto a ser explorado, constituindo-se em uma parceira; o que pode ser percebido pelas formas de se vestir, alimentar-se e demais exemplos que se relacionem com a qualidade de vida, incluindo, ainda, ideologias, filosofias de vida e novos modos de produção (MAFFESOLI, 2005).

Fatores como instrução, informação, oportunidade e motivação são determinantes neste contexto, pois nem todos têm o mesmo acesso a eles. De qualquer forma, manifesta-se, ainda assim, uma criatividade popular, do senso comum, ainda que seja uma criatividade instintiva, servindo de substrato para a diversidade da criação social.

Maffesoli (2005, p. 22) lembra que o corpo social desloca-se de uma "lógica da identidade" (essencialmente individualista) para uma "lógica da identificação" (muito mais coletiva). Desta forma, a cultura do sentimento é conseqüência da atração; os grupos se formam de acordo com as circunstâncias ou os desejos. Características estas peculiares às pessoas e aos grupos envolvidos com as atividades de aventura na natureza.

Acreditando nisso, a afinidade é uma característica despertada nessas práticas e a entrevistada 5 exemplifica-a, citando uma viagem realizada com pessoas muito diferentes, pois, apesar das diferenças, várias afinidades eram encontradas.

Eu acho que o maior elo que existia entre todas elas era a vontade de estar na natureza, a busca por este encontro consigo próprio, do prazer de estar na natureza. Infelizmente, eu tive que abandonar o grupo porque, além de outros problemas com a agência de ecoturismo, eu também estava com problemas no joelho e é engraçado porque, até nessas horas de dificuldade, as pessoas indicavam remédio, médico, etc. Então, as afinidades apareciam em muitas situações. Pessoas que trabalham em empresa, mas desenvolviam algum projeto ambiental e vários outros casos em que você vai conhecendo

Movimento, Porto Alegre, v. 14, n. 02, p. 181-206, maio/agosto de 2008. 
um pouquinho da história de cada um e descobrindo o que as levou pra lá. Por que escolher passar o ano novo subindo e descendo montanha e não estar em outro lugar?

O entrevistado 6, escalador, também percebe este traço comum que permeia as práticas na natureza. Para ele, este tipo de atividade tem uma qualidade ímpar:

[...] é intensa; todo o grupo se une! Como a parte emocional é muito envolvida, ela une as pessoas, o grupo se fortalece e observar isso é muito prazeroso pra mim. Ver o grupo participar, se unir, ficar amigo, é muito legal; você estabelece uma relação de confiança numa velocidade muito grande e muito profunda. As pessoas que se permitem envolver alcançam um nível de relacionamento com relação à confiança que, normalmente, levaria muito tempo.

As experiências do biólogo, entrevistado 7, igualmente, conduzem a esta direção. Quando ele chegou de uma travessia e refletiu sobre ela, percebeu que havia sido o passeio mais bonito que havia feito na vida, um grande aprendizado, e explica por que:

[...] foi muito diferente! Eu aprendi que pra você fazer um passeio como este, de longo tempo, em equipe, essa equipe tem que estar afiada, em vários sentidos. Vai haver problema, conflito? Vai, mas o objetivo final é maior. Reclamação o tempo todo não pode existir; isso não funciona. Um tem que mostrar para o outro que está bem por meio de coisas até bobas (revezar mochilas, revezar o preparo da comida, etc.), mas que darão equilíbrio à viagem. Eu comecei a entender isso tudo, comecei a gostar e quero voltar sempre.

Além da ênfase nas questões da união, parceria e identificação existentes no grupo, é preciso destacar uma contradição observada nas atividades de aventura na natureza: por um lado, existe um grande sentimento de cooperação e união; porém, por outro lado, manifestase uma cobrança de comportamentos (não se deve reclamar das chateações e cansaços, deve-se acompanhar o ritmo imposto na caminhada, etc.).

Movimento, Porto Alegre, v. 14, n. 02, p. 181-206, maio/agosto de 2008. 
A espera pelo outro, em uma caminhada, por exemplo, é parte inerente à prática mais contemplativa, podendo até haver uma certa adaptação ou negociação de ambas as partes, como os discursos dos praticantes, aqui apresentados, mostraram; contudo, tal situação pode causar, igualmente, tensões ou frustrações. $\mathrm{O}$ aprendizado que o biólogo comenta teve uma ressonância positiva como um todo, porém, antes do grupo acertar-se, de fato, ele comentou que, das dez pessoas que iniciaram a travessia com ele, quatro desistiram, justamente por não adequarem-se ao ritmo, postura e interesse da maioria. Ou seja, nas atividades de aventura na natureza também existem certas cobranças de atitudes que, mesmo não sendo explicitamente impositivas, podem causar conflitos e desavenças.

Nesta dinâmica contraditória das atividades de aventura na natureza, prevalecem, no entanto, o espírito de cooperação e a vontade de estar junto, permeando a atividade e fazendo com que a distinção entre o melhor ou o menos capacitado não seja, na maioria das vezes, um fator de exclusão, de fato. Para os praticantes, nas atividades de aventura na natureza, a cooperação, além de ser um estímulo, apresenta-se, também, como uma questão que envolve a segurança do outro e de si mesmo.

A amizade, a confiança, a cooperação e a afinidade ocorrem com freqüência nessas práticas, dando a elas um significado singular. Muitos exemplos poderiam ser citados, como o rafting, em que, dentro do bote, cada integrante pode remar em um sentido diferente (é necessário, algumas vezes, alguns remarem para frente e outros para trás); contudo, isso ocorre em perfeita sintonia, para que a direção desejada seja atingida e o objetivo comum seja alcançado. Ou seja, nas atividades de aventura na natureza, seja remando, escalando ou caminhando, os pontos de vista e as diferenças são respeitados e as metas são atingidas somente a partir disso.

Os discursos dos praticantes são bastante ilustrativos, mostrando que prevalece um certo tipo de acaso, porém, o valor, a admiração, o hobby e o gosto partilhados tornam-se a base, os vetores da ética. Pode-se, ainda, observar uma espécie de narcisismo coletivo, enfatizando a estética, pois promove estilos particulares, um

Movimento, Porto Alegre, v. 14, n. 02, p. 181-206, maio/agosto de 2008. 
modo de vida, uma ideologia, dentre outros exemplos que são da ordem do compartilhamento (MAFFESOLI, 2005).

As atividades de aventura na natureza, por meio da vivência coletiva de emoções e sensações, representam uma das mais recentes práticas fundadoras da vida social, nas quais, por sua vez, o componente lúdico é o efeito e a conseqüência de toda esta sociabilidade vivida.

Ser ou não ser uma aventura é relativo e varia de pessoa para pessoa. Como os grupos são sempre muito heterogêneos sempre haverá, concomitantemente, conflitos e alegrias dos mais diferentes níveis. Não se trata de categorizar a aventura, mas de mostrar a dinâmica tensão das relações nela existente.

Além desta questão da heterogeneidade do grupo e da diversidade de percepções também é interessante refletirmos quando, efetivamente, uma atividade na natureza deixa de ser uma aventura para uma mesma pessoa. Referindo-se a suas experiências pessoais, o entrevistado 1 traz outra importante contribuição.

\begin{abstract}
Acredito que a atividade na natureza é uma aventura quando tem relação com o desconhecido ou com o pouco conhecido. Um local que seja menos desbravado por mim é o meu termômetro de aventura; quanto menos eu conhecer o local e puder ter surpresas de visual, de vegetação, de terreno, mais se torna uma aventura. Quanto mais eu conhecer este lugar, menos aventureiro ele vai ser pra mim.
\end{abstract}

A entrevistada 3 também enriquece a discussão com suas impressões, as quais contêm elementos comuns (o desconhecido) e, também, opostos aos do entrevistado 1 (medo de grandes desafios).

\footnotetext{
O passeio passa a ser uma não aventura quando ele se torna muito comum mesmo e, pra mim, todos esses passeios na serra ainda são muito aventureiros, mas, com o tempo, eles podem deixar de ser.

Eu não sei se eu sou uma pessoa que teve muitas aventuras. Já passei por algumas situações de enfrentar muito frio à noite; receio de aparecer algum bicho do meio do mato pra minha barraca. Eu
}

Movimento, Porto Alegre, v. 14, n. 02, p. 181-206, maio/agosto de 2008. 
sou meio medrosona. Mas só isso! Eu acho que eu nunca passei por momentos de enfrentamentos de muitos desafios, em que eu ficasse tensa e aflita por conta de alguma coisa muito nova.

Uma experiência de aventura na natureza se constitui em colocar à prova competências e capacidades próprias, nas quais o risco e o perigo podem ser avaliados e medidos. Neste contexto, o nível de risco admitido pelos participantes, como ilustrado pelos discursos dos praticantes, é bastante variado. Caminhar por trilhas já conhecidas, por exemplo, pode ser uma atividade de aventura para determinadas pessoas, nas quais elas vivenciam experiências prazerosas, aprendendo algo sobre o local, a cultura, sobre outras pessoas e sobre elas mesmas; sem, entretanto, vivenciarem momentos arriscados.

$\mathrm{O}$ risco pode expor, de fato, o praticante à possibilidade de se machucar ou, até mesmo, de morrer. Habilidades pessoais, decisões corretas e prudentes e auxílio de aparelhos tecnológicos contribuem para aumentar o senso de segurança na atividade. No entanto, para algumas pessoas, o risco parece não ser o componente primordial em uma atividade de aventura na natureza.

A aventura pode ter, portanto, uma estreita relação com obstáculos, não apenas físicos, mas também simbólicos e imaginários, a serem ultrapassados, que não necessariamente são os mais arriscados e difíceis, mas que, de alguma forma, agregam o novo, o desconhecido e o não-explorado.

É possível nos remetermos à Antiguidade, momento em que os viajantes agiam conforme o destino. Ortiz (2000), refletindo sobre as histórias da Odisséia, por exemplo, aponta que os heróis vagavam por territórios desconhecidos sem ter a possibilidade da escolha. Eles perambulavam e aventuravam-se por mares, desertos, montanhas, com o intuito de, na verdade, atender às vontades dos deuses. $\mathrm{O}$ caminho era vivido como uma prova e a aventura como um sofrimento.

Contudo, no mundo contemporâneo, a aventura parece libertarse do peso do sofrimento que a marcava, tornando-se, contrariamente, prazer, excitação, alegria e novo vigor. A aventura atual carrega

Movimento, Porto Alegre, v. 14, n. 02, p. 181-206, maio/agosto de 2008. 
uma diferente conotação; ela passou a ter razões mais relacionadas aos desejos pessoais próprios dos indivíduos que se agrupam conforme interesses comuns. Nesta perspectiva, foi possível observar que espontaneidade, afinidade, solidariedade, liberdade de escolha, confiança, cooperação e coletividade foram focadas, direta e indiretamente, pelos praticantes de atividades de aventura na natureza.

\section{Considerações Finais}

Os indivíduos constituem-se e desenvolvem-se em novas e diferentes condições sociais, econômicas, políticas e culturais. Nesse processo de construção de identidades e de socialização, o lazer é um elemento fundamental.

Existe um certo consenso no que se refere ao lazer como dimensão cultural, vivido por diferentes grupos, havendo cruzamento de intenções e de identidades diversificadas. Neste sentido, pode-se salientar que o processo de mundialização da cultura (ORTIZ, 2000), não produz uma uniformidade cultural, como muitos sugerem existir; contrariamente a isso, ele nos torna conscientes de novos níveis de diversidade e das inúmeras facetas existentes na cultura.

Nesta perspectiva, o desenvolvimento do lazer e do turismo não deve ser considerado simplesmente como uma questão de números - fato este que traz dados interessantes, principalmente para a economia - mas, principalmente, como uma mudança qualitativa de utilização do tempo livre em uma sociedade "dita" globalizada. Igualmente, as viagens não se constituem em meros deslocamentos. Diferentemente disso, são expressões de mudanças na própria concepção de tempo disponível das pessoas, assim como as diferentes formas de vivências no lazer, aqui exemplificadas pelas atividades de aventura na natureza.

A aventura parece ser um corpo estranho à existência humana mas, ao mesmo tempo e paradoxalmente, liga-se ao seu centro. A aventura funciona, de certa forma, como uma síntese de alguns de nossos sonhos e desejos. Neste sentido, Simmel (2000) contribui elucidando que a aventura é o coração pulsante de toda a sociedade.

Mavimento, Porto Alegre, v. 14, n. 02, p. 181-206, maio/agosto de 2008. 
Uma vez que "a unidimensionalidade do pensamento é incapaz de compreender a polivalência da vivência" (MAFFESOLI, 2004, p. 35), acredito que a aventura mostra-se, neste quadro, como um importante desafio para refletirmos sobre a razão e os sentidos, as certezas e as incertezas do mundo contemporâneo, constituindo-se em formas sensíveis de vida social.

A aventura, de acordo com os discursos apresentados, está atrelada à idéia de busca pelo desconhecido e desejo de exploração, ressignificando modelos e, de certa forma, despertando novos comportamentos das pessoas envolvidas.

Neste sentido, pode-se afirmar que os aventureiros contemporâneos se engajam em tais práticas com o objetivo de vivenciarem diferentes experimentações e emoções, as quais têm relações e ressonâncias significativas em todas as esferas da vida humana.

A aventura engloba a busca do brincar com o risco, na maioria das vezes, com um fim em si mesmo, caracterizando o comportamento de pessoas com espírito aventureiro. Por seu forte componente lúdico, a aventura, associada à natureza, pode ser entendida, portanto, como uma metáfora de um novo estilo de vida: o estilo de vida aventureiro. Não se trata, evidentemente, de compreendê-lo em seu sentido estrito, mas de acordo com o contexto geral no qual se exprime, ou seja, a vida social em um dado momento da história. Trata-se de um modo singular de produção de subjetividade e de construção do imaginário coletivo.

A construção social da aventura apresenta elementos centrais de nossa sociedade contemporânea, de suas formas de produção, segregação, diversão, etc. É despertada, nesta perspectiva, a possibilidade de melhor compreensão do outro, da natureza e, principalmente, de nós mesmos.

Por fim, reitero que o fenômeno das atividades de aventura na natureza não pode ser desvendado nos limites dessas discussões; porém, com elas e a partir dos exemplos trazidos, algumas de suas dimensões podem ser contempladas. Sendo assim, as discussões empreendidas tiveram a pretensão de contribuir com novos desafios que se apresentam na esfera do lazer, fortalecendo o repensar sobre a sociabilidade na vida contemporânea, especialmente atrelada à natureza.

Movimento, Porto Alegre, v. 14, n. 02, p. 181-206, maio/agosto de 2008. 
Leisure, Adventure and Risk: reflections about activities in nature

Abstract: This paper reflects on the conceptions of adventure and risk, revealed in activities in nature. The presented speeches are contained in a research, whose boarding works with a universe of reasons, aspirations, values, beliefs and attitudes, corresponding to a deeper space of the processes, relations and phenomena. It was possible to perceive that the adventure activities in nature are carrying of innumerable meanings, related with new discoveries, new challenges, search for the stranger, uncertainty, cooperation, friendship, among others. Such activities understand diverse forms of experimentation, pointing besides to physical risk, the symbolic and imaginary risk.

Keywords: Leisure activities. Adventure. Risk. Nature.

Ocio, Aventura y Riesgo: reflexiones acerca de las actividades de aventura

Resumen: Esto texto presenta reflexiones acerca de los conceptos de la aventura y del riesgo, revelados en actividades en naturaleza. Los discursos se encuentran en una investigación, que trabaja con un universo de razones, de aspiraciones, valores, creencias y de actitudes, correspondiendo a un espacio más profundo de los procesos, de las relaciones y de los fenómenos. Es posible percibir que las actividades de la aventura en naturaleza tienen muchos significados, relacionados con nuevos descubrimientos, nuevos desafíos, incertidumbre, cooperación, amistad, entre otras. Tales actividades presentan diversas formas de experimentación, señalando más que el riesgo físico: el riesgo simbólico y imaginario.

Palabras-clave: Actividades recreativas. Aventura. Riesgo. Naturaleza.

\section{REFERÊNCIAS}

BRANDÃO, Carlos R. Pesquisa participante. São Paulo: Brasiliense, 1988.

BRASIL. Ministério do Meio Ambiente. Diagnóstico da visitação em parques nacionais e estaduais. Disponível em: <http://www.mma.gov.br/estruturas/sbs_dap/ _arquivos/diagnostico_da_visitacao_em_parques.pdf> Acesso em: 26 jan. 2006.

Movimento, Porto Alegre, v. 14, n. 02, p. 181-206, maio/agosto de 2008. 
CARVALHO, Artur. Esportes na Natureza: Estratégias de Ensino do Canionismo para Pessoas com Deficiência Visual. Dissertação (Mestrado em Educação Física), Faculdade de Educação Física, Unicamp, Campinas (SP), 2005.

DIAS, Viviane K. As atividades de aventura na natureza e o idoso: redimensionando o lazer. In: SCHWARTZ, Gisele M. Aventuras na natureza: consolidando significados. Jundiaí: Fontoura, 2006. p. 237-251.

DONNELLY, Peter; WILLIANS, Trevor. Subcultural production, reproduction and trasformation in climbing. International Review for the Sociology of Sport, Brighton, n. 20, p. 3-15, 1985.

EWERT, Alan. Outdoor adventure pursuits: foundations, models, and theories. Columbus: Horizons, 1989.

EWERT, Alan; HOLLENHORST, S. Testing the adventure model: Empirical support for a model of risk recreation participation. Journal of Leisure Research, Champaign, n. 21, p. 124-139, 1989.

FEATHERSTONE, Mike. O desmanche da cultura: globalização, pós-modernismo e identidade. São Paulo: Studio Nobel - SESC, 1997.

FERREIRA, Aurélio B. H. Novo Dicionário de Língua Portuguesa. 13. Imp. Rio de Janeiro: Nova Fronteira, 1975.

GEERTZ, Clifford. Nova luz sobre a antropologia. Rio de Janeiro: Jorge Zahar, 2001.

GIMENO, José M. R.; FRA, Elena P.; MONTESINOS, José L. G.; MILLÁN, Ismael G. La prevención de drogodependencias mediante actividades cooperativas de riesgo y aventura. Apunts: Educación Física y Deportes, Barcelona, n. 59, p. 46-54, 2000.

INACIO, H. L. D.; SILVA, A. P. S.; PERETTI, E.; LIESENFELD, P. A. Travessuras e Artes na natureza: movimentos de uma sinfonia. In: SILVA, Ana M.; DAMIANI, Iara R. (Org.). Práticas corporais: trilhando e compar(trilhando) as ações em Educação Física. Florianópolis: Nauemblu Ciência e Arte, 2005. v. 2, p. 81-105.

KLINK, Amyr. Mar sem fim: 360ํa ao redor da Antártica. São Paulo: Cia. das Letras, 2000.

LE BRETON, David. Risco e lazer na natureza. In: MARINHO, Alcyane; BRUHNS, Heloisa T. (Org.). Viagens, Lazer e Esporte: o espaço da natureza. São Paulo: Manole, 2006. p. 94-117.

LUCHIARI, Maria T.D.P. Turismo e meio ambiente na mitificação dos lugares. Turismo em Análise. Revista do Dep. de Relações Públicas, Propaganda e Turismo, São Paulo, v. 11, n. 1, p. 35-43, maio 2000.

MAFFESOLI, Michel. O mistério da conjunção: ensaios sobre comunicação, corpo e socialidade. Tradução de Juremir Machado da Silva. Porto Alegre: Sulina, 2005.

Movimento, Porto Alegre, v. 14, n. 02, p. 181-206, maio/agosto de 2008. 
MAFFESOLI, Michel. Notas sobre a pós-modernidade: o lugar faz o elo. Tradução de Vera Ribeiro. Rio de Janeiro: Atlântica, 2004.

MAFFESOLI, Michel. A contemplação do mundo. Tradução de Francisco Franke Settineri. Porto Alegre: Artes e Ofícios, 1995.

MARINHO, Alcyane. As diferentes interfaces da aventura na natureza: reflexões sobre a sociabilidade na vida contemporânea. 2006. Tese (Doutorado em Educação Física) - Faculdade de Educação Física. Universidade Estadual de Campinas, Campinas (SP), 2006.

MARINHO, Alcyane. Lazer, natureza e aventura: compartilhando emoções e compromissos. Revista Brasileira de Ciências do Esporte, Campinas, v. 22, n. 2, p. 143-153, 2001.

MARINHO, Alcyane; BRUHNS, Heloisa T. Body relationships in an urban adventure setting. Journal of Leisure Studies. Forest Row, v. 24, n. 3, p. 223-238, 2005.

MARINHO, Alcyane; BRUHNS, Heloisa T. (Org.). Turismo, lazer e natureza. São Paulo: Manole, 2003.

MARINHO, Alcyane; BRUHNS, Heloisa T. La escalada y las actividades de aventura: realizando sueños lúcidos y lúdicos. Apunts: Educación Física y Deportes, Barcelona, n. 65, p. 105-110, 2001.

MINAYO, Maria C. S. Pesquisa social: teoria, método e criatividade. Petrópolis: Vozes, 1993.

MUNSTER, Mey A. Corpo e natureza: trilhando sensações, percepções e movimentos. In: VERARDI, Paulo H.; PEDRINELLI, Verena J. (Org.). Desafiando as diferenças. 2.ed. São Paulo: SESC, 2004.

ORTIZ, Renato. Um outro território: ensaios sobre a mundialização. São Paulo: Olho d'água, 2000.

SCHWARTZ, Gisele M. Emoção, aventura e risco - a dinâmica metafórica dos novos estilos. In: BURGOS, Miria S.; PINTO, Leila M. S. M. Lazer e estilo de vida. Santa Cruz do Sul: EDUNISC, 2002. p. 139-168.

SENNETT, Richard. A corrosão do caráter: conseqüências pessoais do trabalho no novo capitalismo. 4.ed. Tradução de Marcos Santarrita. São Paulo: Record, 2000.

SEVERINO, Antonio J. M. Metodologia do trabalho científico. São Paulo: Autores Associados: Cortez, 1992.

SIMMEL, Georg. The adventure. In: FRISBY, David; FEATHERSTONE, Mike (Ed.). Simmel on Culture. London: Sage, 2000. p. 221-232.

SIMMEL, Georg. Sobre la aventura: ensayos filosóficos. Tradução de Gustau Muñoz e Salvador Mas. Barcelona: Península, 1988.

Movimento, Porto Alegre, v. 14, n. 02, p. 181-206, maio/agosto de 2008. 
SWARBROOKE, John et al. Turismo de aventura: conceitos e estudos de casos. Tradução de Marise Philbois Toledo. Rio de Janeiro: Elsevier, 2003.

WALLE, Alf $\mathrm{H}$. Pursuing risk or insight: marketing adventures. Annals of Tourism Research, Kidlington Oxford, v.24, n.2, p.265-282, 1997.

WEBER, Karen. Outdoor adventure tourism: a review of research approaches. Annals of Tourism Research, Kidlington Oxford, v.28, n.2, p.360-377, 2001.

Movimento, Porto Alegre, v. 14, n. 02, p. 181-206, maio/agosto de 2008. 